\title{
Prenatal treatment with rapamycin restores enhanced hippocampal mGluR-LTD and mushroom spine size in a Down's syndrome mouse model
}

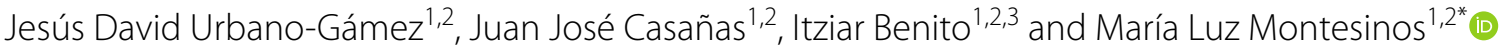

\begin{abstract}
Down syndrome (DS) is the most frequent genetic cause of intellectual disability including hippocampal-dependent memory deficits. We have previously reported hippocampal mTOR (mammalian target of rapamycin) hyperactivation, and related plasticity as well as memory deficits in Ts 1Cje mice, a DS experimental model. Here we characterize the proteome of hippocampal synaptoneurosomes (SNs) from these mice, and found a predicted alteration of synaptic plasticity pathways, including long term depression (LTD). Accordingly, mGluR-LTD (metabotropic Glutamate Receptor-LTD) is enhanced in the hippocampus of Ts1Cje mice and this is correlated with an increased proportion of a particular category of mushroom spines in hippocampal pyramidal neurons. Remarkably, prenatal treatment of these mice with rapamycin has a positive pharmacological effect on both phenotypes, supporting the therapeutic potential of rapamycin/rapalogs for DS intellectual disability.
\end{abstract}

Keywords: mGluR-LTD, mTOR, Dendritic spines, Proteomics, Down syndrome, Synaptoneurosomes, Trisomy 21

\section{Introduction}

DS, also known as trisomy 21, is one of the most common causes of intellectual disability. Among other difficulties, DS patients experience learning and memory deficits that evidence hippocampal dysfunctions [1]. We have previously shown that synaptic local translation, a key process for plasticity and hippocampal-dependent memory, is deregulated in the DS mouse model Ts1Cje [2] due to mTOR hyperactivation [3]. Accordingly, mTOR hyperactivation has been also found in subjects with DS $[4,5]$. In Ts1Cje mice, mTOR hyperactivation seems to be caused by increased levels of Brain Derived Neurotrophic Factor (BDNF) that saturate the BDNF-TrkB-Akt-mTOR

\footnotetext{
*Correspondence: mlmontesinos@us.es

${ }^{1}$ Departamento de Fisiología Médica Y Biofísica, Universidad de Sevilla, Av. Sánchez-Pizjuán 4, 41009 Sevilla, Spain
}

Full list of author information is available at the end of the article signaling axis $[3,6]$. Furthermore, we also found that the BDNF-dependent Long-Term Potentiation (LTP) is abolished in the Ts1Cje hippocampus, and that the specific mTOR inhibitor rapamycin fully restored this type of plasticity [7]. Moreover, we observed that the impaired persistence of long-term memory (LTM) in the Barnes maze of Ts1Cje animals was also restored by rapamycin treatment [7].

The mTOR pathway is known to participate in other forms of plasticity, such as mGluR-LTD. This is mediated by group I metabotropic glutamate receptors and relies on protein translation [8]. mTOR forms two different complexes: mTORC1, which contains, among other components, the defining protein RAPTOR (Regulatory Associated Protein of mTOR), and mTORC2, which contains RICTOR (Rapamycin-Insensitive Companion of TOR). In neurons, mTORC1 is mainly involved in translational control, mitochondrial function and autophagy original author(s) and the source, provide a link to the Creative Commons licence, and indicate if changes were made. The images or other third party material in this article are included in the article's Creative Commons licence, unless indicated otherwise in a credit line to the material. If material is not included in the article's Creative Commons licence and your intended use is not permitted by statutory regulation or exceeds the permitted use, you will need to obtain permission directly from the copyright holder. To view a copy of this licence, visit http://creativecommons.org/licenses/by/4.0/. The Creative Commons Public Domain Dedication waiver (http://creativeco mmons.org/publicdomain/zero/1.0/) applies to the data made available in this article, unless otherwise stated in a credit line to the data. 
regulation, whereas mTORC2 regulates actin cytoskeleton (for a review see [9]). It is well known that rapamycin blocks hippocampal mGluR-LTD [10], initially suggesting that protein synthesis mediated by mTORC1 is necessary for this plasticity. Nevertheless, chronic treatment or high concentrations of rapamycin also inhibit mTORC2 [11], and, moreover, it has been recently reported that mTORC2, but not mTORC1, is required for mGluRLTD [12]. In line with these results, it is well established that inhibiting actin polymerization/depolymerization blocks mGluR-LTD [13] and that dendritic spines elongate in response to mGluR activation, correlating with AMPA receptor (AMPAR) endocytosis [13, 14]. In fact, mGluR activation induces rapid local translation of proteins involved in AMPAR internalization such as Arc/ Arg3.1 (Activity Regulated Cytoskeleton-associated protein), OPHN1 (oligophrenin-1), MAP1B (Microtubule Associated Protein 1B) and STEP (Striatal-Enriched Protein Phosphatase) [15]. These proteins are targets of FMRP (Fragile X Mental Retardation Protein, encoded by the $F M R 1$ gene), a key regulator of local translation. Since mGluR-LTD is enhanced in FMR1 knockout mice, it has been proposed that FMRP serves as a brake on mGluR-stimulated protein synthesis (for a review see [16]). Moreover, it has been shown that hippocampal mGluR-LTD requires the rapid synthesis and degradation of FMRP [17]. Despite the extensive work, the definitive comprehension of the signaling pathways that contribute to protein synthesis necessary for mGluR-LTD remains elusive although roles for mTORC1 and ERK (Extracellular signal-regulated kinase) have been proposed [16].

To gain insight into the signaling pathways relevant for synaptic plasticity altered in Ts1Cje, we have characterized the proteome of hippocampal SNs from wildtype (WT) and Ts1Cje mice by iTRAQ (isobaric tag for relative and absolute quantitation). Interestingly, mitochondrial function, calcium signaling and, remarkably, synaptic plasticity pathways, including LTD, were predicted to be altered in trisomic mice. Accordingly, we have found that the hippocampal mGluR-LTD is enhanced in Ts1Cje animals. Additionally, we have evaluated the effect of rapamycin on dendritic spine density and morphology. We found that prenatal treatment with rapamycin did not recover the decreased density of dendritic spines in Ts1Cje offspring but, interestingly, recovered the alterations observed in mushroom spine size. Strikingly, prenatal rapamycin treatment also had a recovery effect on the mGluR-LTD in Ts1Cje hippocampus. Together, these results extend the evidence that supports the possible benefits of rapamycin for synaptic plasticity in the context of DS.

\section{Materials and methods}

\section{Animals}

Partial trisomic Ts1Cje mice [2] were purchased from Jackson Laboratories (RRID:IMSR_JAX:004861) and, as recommended by the supplier, were maintained on a mixed genetic background for improving strain viability, by backcrossing Ts1Cje males to B6C3F1 hybrid females (supplied by Charles River, RRID:IMSR_CRL:31). The Ts1Cje mice harbour two copies of the WT murine chromosome 16 (MMU16) and an additional copy of distal MMU16 (containing 96 genes) translocated onto MMU12 [2]. Sets of WT males and Ts1Cje littermates were used in the experiments. A total number of 48 animals (22 WT and 26 Ts1Cje) were used. No randomization was performed to allocate subjects in the study. Thus, they were arbitrarily allocated to the specific treatments or procedures. Blind animals homozygous for the retinal degeneration mutation $P d e 6 b^{\text {rd1 }}$, which segregates in the Ts1Cje colony [2], were not used. Experiments were carried out according to the European Union directive for the use of laboratory animals. All the protocols were approved by the Regional Government (Junta de Andalucía, Spain) Ethical Committee (Ref. No. 24/05/2016/097). This study was not pre-registered. Mice were housed in cages and subjected to a normal $12 \mathrm{~h}$ light-12 h dark cycle. In the case of adult and juvenile (P21-P30; P, postnatal day) mice, 4 animals per cage, with food and water ad libitum, were housed. P18 mice, used in Golgi experiments, were housed with their mother.

Animals were genotyped following the protocols recommended by Jackson Laboratories. For determining partial trisomy, the neomycin resistance generic primers oIMR0013 (5'-CTTGGGTGGAGAGGCTATTC) and oIMR0014 (5'-AGGTGAGATGACAGGAGATC), which generate a 280 bp NEO band (only present in trisomic mice), as well as the internal control Tcrd primers oIMR0015 (5'-CAAATGTTGCTTGTCTGGTG) and oIMR0015 (5'-GTCAGTCGAGTGCACAGTTT), which amplify a $200 \mathrm{bp}$ fragment (both in trisomic and WT mice), were used in standard PCR reactions. For detecting the Pde $6 b^{r d 1}$ mutation, the oIMR2093 (mutant; 5'-AAGCTAGCTGCAGTAACGCCATTT), oIMR2094 (WT; 5'-ACCTGCATGTGAACCCAGTATTCTATC) and oIMR2095 (common; 5'-CTACAGCCCCTCTCC AAGGTTTATAG) primers were used in standard PCR reactions. These primers produce a $560 \mathrm{bp}$ band in mutants, a $240 \mathrm{bp}$ band in WT, and both in heterozygote animals.

Adult animals were sacrificed by cervical dislocation. P18-P30 animals, used for electrophysiology and Golgi staining experiments, were anaesthetized by intraperitoneal injection of $2 \%$ tribromoethanol (Sigma, Ref. T48402) at a dose of $300 \mathrm{mg} / \mathrm{kg}$, and then decapitated. 
Finally, P0 mice used for primary culture of neurons were directly decapitated.

\section{Rapamycin treatment}

Rapamycin (Selleckchem, Ref. S1039) was dissolved at $0.1 \mathrm{mg} / \mathrm{ml}$ in saline buffer containing 1 ethanol (Merck, Ref. 100983), 0.25\% Tween ${ }^{\circledR} 80$ (Sigma-Aldrich, Ref. P4780) and $0.25 \%$ polyethylene glycol 400 (Aldrich, Ref. 202398) [18]. A single intraperitoneal injection of rapamycin $(1 \mathrm{mg} / \mathrm{kg})$ was applied to pregnant dams between E15 and E17 as previously described [18]. Control pregnant dams were not injected with vehicle.

\section{Synaptoneurosomes preparation}

SNs were prepared as previously described [19]. Briefly, hippocampi from adult WT or Ts1Cje mice (2-4 month old, 3 mice per group) were rapidly dissected and homogenized in $12 \mathrm{ml}$ of homogenization solution consisting in: $10 \mathrm{mM}$ Hepes (Sigma, Ref. H4034), pH 7.4; $320 \mathrm{mM}$ sucrose (Sigma, Ref. S0389); $1.0 \mathrm{mM} \mathrm{MgSO}_{4}$ (Sigma, Ref. M7506); protease inhibitors leupeptin $(10 \mu \mathrm{M})$, aprotinin $(2 \mu \mathrm{g} / \mathrm{ml})$, and pepstatin $(1 \mu \mathrm{M})$ (Sigma, Ref. L2884, A1153 and P5318, respectively), with a glass-teflon Dounce homogenizer. The homogenate was centrifuged (1000g for $10 \mathrm{~min}$ at $4{ }^{\circ} \mathrm{C}$ ), and the pellet was subjected to an Optiprep discontinuous gradient (9-40\% Optiprep; Sigma, Ref. D1556). After centrifugation $(16,500 g$ for $30 \mathrm{~min}$ at $4{ }^{\circ} \mathrm{C}$ ), the material from the first band (fraction O1) was recovered and subjected to discontinuous Percoll (Sigma, Ref. P1644) gradient (10-25\%) centrifugation $\left(32,400 \mathrm{~g}\right.$ for $20 \mathrm{~min}$ at $\left.4{ }^{\circ} \mathrm{C}\right)$. The material from the fourth band (fraction 1P4), which is highly enriched in SNs, was recovered, washed with buffer, rapidly frozen and stored at $-80^{\circ} \mathrm{C}$ until iTRAQ proteomics.

\section{ITRAQ labeling and analysis}

Protein extraction, iTRAQ labeling and tandem mass spectrometry analysis was carried out at the Instituto de Biomedicina de Sevilla (IBiS) Proteomic Service. Briefly, synaptoneurosomal proteins were extracted using a lysis buffer that contained SDS, supplemented with protease inhibitors (Sigma, Ref. P8340), phosphatase inhibitor cocktails I and II (Sigma, Ref. P2850 and P5726), and benzonase (Sigma, Ref. E8263). After incubation for $1 \mathrm{~h}$, the samples were centrifuged for $15 \mathrm{~min}$ at $14,000 \mathrm{rpm}$ in a refrigerated bench-top microfuge. Proteins present in the supernatant were quantified following iTRAQ labeling (AB ScieX, Ref. 4390811) essentially following the manufacturer's instructions, omitting the protein precipitation step in order to conserve minority proteins. $50 \mu \mathrm{g}$ of proteins were labeled for each experimental condition in duplicates. Data were analyzed using the Proteome Discoverer 1.4 software (Thermo), setting the
False Discovery Rate (FDR) of both proteins and peptides identification to be less than 0.01 .

\section{Proteomic analyses}

To verify that SNs preparations used in ITRAQ experiments were enriched in synaptic proteins, a PANTHER (Protein ANalysis THrough Evolutionary Relationships; version 16.0) analysis was carried out [20]. An overrepresentation test was performed, selecting the entire Mus musculus genome (21,988 proteins) and the PANTHER GO-Slim Cellular Component annotation data set. Bonferroni correction for multiple testing was applied.

Ingenuity Pathway Analysis (IPA, Fall release September 2019) was performed for both up- and downregulated proteins, considering a cutoff of 1.2-fold. This cutoff was established by analyzing the protein level variations observed in the WT sample replicate and determining the boundaries within the $80 \%$ best fitting replicate data.

The Ingenuity Knowledge Base (genes only) set was used as reference. All the molecules and/or relationships included in the analysis were experimentally observed, either in the mouse, rat, human nervous system tissue or neural (astrocytes or neurons) cells. The IPA software generates a list of significantly affected canonical pathways based on two parameters, the $\mathrm{p}$-value and the $\mathrm{Z}$-score. The p-value, calculated with the right-tailed Fisher Exact Test, is a measure of the probability that a particular pathway were enriched in the set of deregulated proteins due to random chance. To enhance the stringency of the analysis, we considered only pathways with a $\mathrm{p}$-value $\leq 0.005$ (i.e., $-\log _{10}(\mathrm{p}$-value $) \geq 2.3$ ). Considering the protein level changes observed in the set of deregulated proteins, the canonical pathways identified are predicted to be either activated or inhibited applying the IPA Z-score algorithm. A positive Z-score value indicates that a pathway is predicted to be activated, and a negative Z-score indicates its inhibition. Canonical pathways which are not eligible for activity analysis by the IPA are marked as N/A.

\section{Antibodies}

We used anti-FMRP (Abcam; Ref. ab69815, RRID:AB_1209562), anti-MAP2 (Merck Millipore; Ref. MAB378, RRID:AB_94967), anti-LC3B (Cell Signaling; Ref. \#2775, RRID:AB_915950), and anti-TOMM20 (Novus; Ref. NBP1-81556, RRID:AB_11003249) as primary antibodies, while horseradish peroxidase (HRP)-conjugated anti-rabbit (Promega; Cat.W4011, RRID:AB_430833), Alexa Fluor 555 goat anti-rabbit (Thermo Fisher Scientific; Cat\# A-21429, RRID:AB_2535850), and Alexa Fluor 488 goat antimouse (Thermo Fisher Scientific; Cat\# A-11001, RRID:AB_2534069) were used as secondary antibodies. 


\section{Western blot}

Western blots were performed as previously described [21]. Adult (4-5 month-old) male mice were used. Briefly, total hippocampal protein extracts were prepared for each individual by mechanical tissue homogenization in extraction buffer containing: $50 \mathrm{mM}$ Tris (Sigma, Ref. 93352) buffer (pH 7.4), 0.5\% Triton X-100 (Sigma, Ref. T8787), $150 \mathrm{mM} \mathrm{NaCl}$ (Sigma-Aldrich, Ref. S7653), 1 mM EDTA (Sigma, Ref. E5134), 3\% SDS (Sigma, Ref. 05030), protease (Sigma, Ref. P8340) and phosphatase inhibitor cocktails (Sigma, Ref. P5726 and P0044). Protein extracts were resolved by SDS-PAGE on MiniPROTEAN $^{\circledR}$ TGX Stain-Free ${ }^{\mathrm{TM}}$ precast gels (BioRad, Ref. 1704156). Proteins were transferred to polyvinylidene difluoride (PVDF) membranes (Trans-blot ${ }^{\circledR}$ Turbo $^{\mathrm{TM}}$ Transfer Pack, Ref. 1704156). Membranes were incubated with blocking solution (1\% non fat dry milk in TBS-T buffer; TBS-T buffer is $20 \mathrm{mM}$ Tris buffer [pH 7.5], $150 \mathrm{mM}$ $\mathrm{NaCl}$, and $0.1 \%$ Tween ${ }^{\circledR} 20$ ) for $1 \mathrm{~h}$ at RT, then incubated overnight at $4{ }^{\circ} \mathrm{C}$ with the appropriate primary antibody (dilution 1:1,000). After washing with TBS-T, the membranes were incubated with the HPR-conjugated secondary antibodies diluted in blocking solution (dilution 1:20,000 for FMRP immunoblot, 1:5,000 for LC3B immunoblot, and 1:2,000 for TOMM20) for $1 \mathrm{~h}$ at RT. HRPconjugated secondary antibodies were detected with the WesternBright Quantum HRP Substrate (Advansta, Ref. K-12042-D10) and chemiluminiscence measured on a ChemiDoc XRS (BioRad) imager.

\section{Immunocytochemistry}

Hippocampal cultures from P0 WT or Ts1Cje littermates were established as previously described [22]. Briefly, hippocampi from $5 \mathrm{WT}$ and $5 \mathrm{Ts} 1 \mathrm{Cje}$ mice were dissected in HBSS medium (Gibco, Ref. 14175-095) and mechanically dissociated in DB1 culture medium (Biowest, Ref. L0104) after treatment with $0.2 \%$ trypsin (Gibco, Ref. 15090-046) for $10 \mathrm{~min}$. Cells were cultured in Neurobasal A (Gibco, Ref. 100888-022) supplemented with B27 (Gibco, Ref. 17504-044), Glutamax (Gibco, Ref. 35050-061) and penicillin/streptomycin (Gibco, Ref. 15140-122). To inhibit glial growth, $0.3 \mathrm{mM}$ 5-fluoro-2'-deoxyuridine (SigmaAldrich, Ref. 856657) and $0.8 \mathrm{mM}$ uridine (SigmaAldrich, Ref. U3003) were added after $48 \mathrm{~h}$ in culture. After 14 days in vitro (DIV), cells were fixed with $4 \%$ paraformaldehyde (PFA, Sigma-Aldrich, Ref. P6148) in phosphate-buffered saline (PBS, Panreac Applichem, Ref. A9177) and subjected to dual immunocytochemistry using antibodies against FMRP (1:250 dilution) and MAP2 (1:1,000 dilution). Thus, after fixation, cells were washed 3 times with PBS and incubated with blocking solution $(0.1 \%$ Triton X-100, and $10 \%$ fetal bovine serum in PBS) for $1 \mathrm{~h}$ at RT. Then, primary antibodies, diluted in blocking solution, were applied overnight at $4{ }^{\circ} \mathrm{C}$. After washing 3 times with PBS for $10 \mathrm{~min}$, cells were incubated with the corresponding secondary antibodies (dilution 1:1,000) for $1 \mathrm{~h}$ at RT, then washed in PBS. Confocal microscopy images were acquired and processed as previously described [21]. The mean pixel intensity for the corresponding immunofluorescent FMRP signal in dendrites was determined (in arbitrary units, a.u.) using a Matlab (Mathworks) routine previously established [3].

\section{Electrophysiological recordings}

Hippocampal slices were prepared from P21-P30 WT and Ts1Cje mice. Since we intended to correlate electrophysiological and behavioural results, and previous behavioural experiments performed in the laboratory gave a high variability when using females, only male mice were used, for the sake of reproducibility. Mice were anesthetized and brains were removed in an ice-cold artificial cerebrospinal fluid with partial substitution of $\mathrm{Na}$ with sucrose (ACSFs) with constant flux of carbogen (5\% $\mathrm{CO}_{2}$; rest $\left.\mathrm{O}_{2} ; \mathrm{H}_{2} \mathrm{O}<5 \mathrm{ppm}\right)$. ACSFs composition was: $2.5 \mathrm{mM} \mathrm{KCl}$ (Sigma, Ref. P9541); $1.25 \mathrm{mM} \mathrm{NaH}_{2} \mathrm{PO}_{4}$ $\left(2 \mathrm{H}_{2} \mathrm{O}\right)$ (Sigma, Ref. P71505); $26 \mathrm{mM} \mathrm{NaHCO}_{3}$ (Sigma, Ref. S5761); 25 mM glucose (Sigma, Ref. G5400); $0.5 \mathrm{mM}$ $\mathrm{CaCl}_{2}\left(2 \mathrm{H}_{2} \mathrm{O}\right)$ (Sigma, Ref. 223506); $4 \mathrm{mM} \mathrm{MgSO}_{4}$ $\left(7 \mathrm{H}_{2} \mathrm{O}\right)$ (Sigma, Ref. 63138); $185 \mathrm{mM}$ sucrose (Sigma, Ref. P84097). Brains were positioned in the cutting chamber over a thin film of ethyl cyanoacrylate and were submerged in cold ACSFs. $350 \mu \mathrm{m}$ horizontal slices were obtained using a vibratome (Vibratome 3000, Sectioning System) and both hippocampi were isolated in each slice preserving entorhinal cortex adjacent to the hippocampal formation. Slices were incubated in ACSF (126 mM NaCl; $3 \mathrm{mM} \mathrm{KCl} ; 1.3 \mathrm{mM} \mathrm{MgSO}_{4}\left(7 \mathrm{H}_{2} \mathrm{O}\right) ; 2 \mathrm{mM} \mathrm{CaCl}_{2}\left(2 \mathrm{H}_{2} \mathrm{O}\right)$; $1.25 \mathrm{mM} \mathrm{NaH}_{2} \mathrm{PO}_{4}\left(2 \mathrm{H}_{2} \mathrm{O}\right) ; 24 \mathrm{mM} \mathrm{NaHCO}_{3} ; 10 \mathrm{mM}$ glucose) for $30 \mathrm{~min}$ at $34{ }^{\circ} \mathrm{C}$. Then, slices were incubated for at least $2 \mathrm{~h}$ in ACSF at room temperature (RT; $22-25{ }^{\circ} \mathrm{C}$ ) before recording, keeping constant the flux of carbogen. Slices were transferred to a 3D-MEA chamber (MultiChannel Systems, Ref. 60-3DMEA200/12/50iR-gr) and stayed at least $10 \mathrm{~min}$ before stimulation with a $2 \mathrm{ml} /$ min flux rate of ACSF. All the registers were performed at RT. The experimenter was blind to the genotype and treatment of the animals during experimentation and data analysis.

The 3D-MEA devices have 59 conical TiN electrodes with $12 \mu \mathrm{m}$ diameter $(100 \mu \mathrm{m}$ in the base of the electrode) and $50 \mu \mathrm{m}$ high, distributed in an $8 \times 8$ matrix with an internal reference electrode at the position 15 (column 1 , row 5). The inter-electrode distance is $200 \mu \mathrm{m}$. The isolation material used for these devices' circuitry is SiN and the base is made out of glass. 
Slices were stimulated at the Schaffer collateral pathway in the CA1 region of hippocampus using a biphasic square pulse (negative phase-positive phase; $100 \mathrm{~ms}$ per phase) at $0.0167 \mathrm{~Hz}$ (1 stimulus per minute). Slices showing field excitatory postsynaptic potential (fEPSP) amplitude lower than $100 \mu \mathrm{V}$ for test stimulation $(-/+1750 \mathrm{mV})$ in the $\mathrm{CA} 1$ region were discarded. Input/ output (I/O) curve was performed reaching the limits of the system (750-4000 mV; 3 stimuli per amplitude) and baseline was established at $60 \%$ of the highest response obtained at the maximum voltage applied. After baseline stabilization, $100 \mu \mathrm{M}$ (S)-3,5-Dihydroxyphenylglycine (DHPG; Sigma-Aldrich, Ref. D-3689) in ACSF was bath applied at a flow rate of $2 \mathrm{ml} / \mathrm{min}$ for $5 \mathrm{~min}$. DHPG-long term depression (DHPG-LTD) was recorded for $1 \mathrm{~h}$ after treatment. In order to determine the synaptic efficacy, the slope of the initial fEPSP curve was measured in the segment comprised between the 10-90\% of the curve amplitude. Recordings were acquired at 10,000 $\mathrm{Hz}$.

Electrophysiological results are presented as the mean \pm SEM (standard error of the mean) normalized to the baseline slope mean. For statistical analysis, a Student's t-test was performed for compared experimental groups. Normalized slope at the minute 60 after DHPG treatment initiation was used for comparisons.

\section{Golgi staining and spine morphology analysis}

WT and Ts1Cje P18 mice were anesthetized and both hemispheres were separated, and the cerebellum was removed. A FD Rapid Golgi stain kit (FD NeuroTechnologies INC, Ref. PK401A) was used following the manufacturer guidelines. After the staining process, $100 \mu \mathrm{m}$ coronal slices were prepared using a cryostat (Leica CM1950). Slices were deposited over Menzel-Gläser Superfrost PLUS microscope slides (ThermoScientific, Ref. J1800AMNZ) and covered with a thin gelatine coat (Gelatine Gold; Panreac DC, Ref. 251336).

Secondary dendrites images were acquired from the hippocampal CA1 stratum radiatum region, at a $1,600 \times 1,200$ pixel resolution, using an Olympus BX61 microscope (CellSens software). For spine morphology analysis, image acquisition was made using an UPlanSApo60x/1.35 oil objective, with a $10 \times$ ocular and an additional $2 \times$ magnification. For spine density analysis, images were acquired using an UPlanApo40x/0.85 air objective, with a $10 \times$ ocular, and an additional $2 \times$ magnification. To determine dendritic spine density, spines were manually counted, and the branch longitude was measured using ImageJ software. For spine morphology analysis, spines perimeters were manually defined, and the head diameter was measured using ImageJ software. The experimenter was blind to sample genotype and treatment during experiment and data analysis.

\section{Statistical analysis}

Predetermined sample calculation was not performed. Sample size was determined based on published studies in the field or in animal availability. The quantitative data are presented as the means and SEM. No test for outliers was performed. All data points were included. The GraphPad Prism software (version 5.00) was used. D'Agostino and Pearson omnibus normality test was first performed, in order to apply either a Student's t-test or a Mann-Whitney rank sum test for mean comparisons. $p$ values are indicated through the text and figure legends.

\section{Results}

Proteomic analysis of hippocampal SNs from Ts1Cje mice

In a previous work we found that Ts1Cje mice showed impaired BDNF-LTP, which was restored by the mTOR inhibitor rapamycin [7]. In order to identify synaptic differences that could account for plasticity and memory deficits in Ts1Cje mice we performed a proteomic analysis of hippocampal SNs isolated from WT and Ts1Cje mice.

Protein samples were subjected iTRAQ proteomics. Thus, from each SNs sample, duplicates were labeled, and the relative amount of each detected protein was referenced to one of the WT samples (Additional file 1: Table S1). 1,890 proteins were identified by at least two unique peptides (Additional file 1: Table S2). Proteins not detected in all the samples (4 proteins) as well as technical replicates with $\mathrm{CV} \%>30 \%$ (19 proteins) were removed. The geometric mean of the relative protein amount was calculated (Additional file 1: Table S3) and used in the subsequent analysis by IPA software.

To verify that the detected proteins were mainly synaptic, the list of proteins in Additional file 1: Table S3 was subjected to a PANTHER overrepresentation test [20]. The PANTHER Go-Slim Cellular Component annotation dataset was selected. Thus, sets of related proteins overrepresented into the SNs, compared with the complete mouse genome, were identified. A high enrichment in pre- and post-synaptic proteins was evidenced (Fig. 1 and Additional file 1: Table S4), confirming the quality of the SNs preparations.

From the 1,867 proteins initially included in the IPA, 12 resulted to be unmapped, and from the 1,855 mapped identities, IPA considered 1,824 of them as "analysis-ready".

Considering a 1.2-fold cutoff (see "Materials and methods"), 116 proteins were found to be deregulated (108 upand 8 down-regulated) in Ts1Cje SNs compared to WT SNs (Additional file 2: Table S5).

Attending to the Fischer p-value, IPA revealed that, the mitochondrial dysfunction canonical pathway, and the partially overlapping oxidative phosphorylation and 


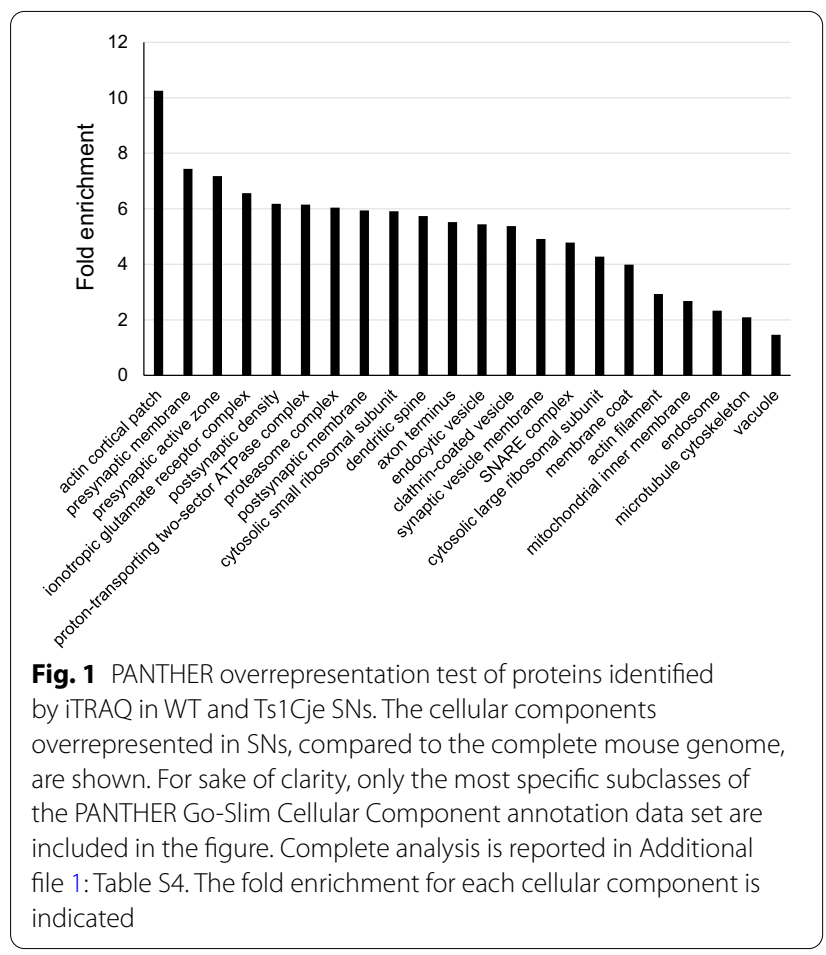

sirtuin signaling pathways were among the most significantly enriched in the set of proteins affected in Ts1Cje SNs (Fig. 2, Table 1 and Additional file 2: Table S6). Accordingly, mitochondrial alterations have been described in DS and DS mouse models [23-25]. In fact, it has been recently shown that reduced autophagy/ mitophagy due to mTOR hyperactivation produces damaged mitochondria accumulation in DS fibroblasts [26]. In agreement with these data, the levels of the B-II isoform of Microtubule-associated protein 1A/1Blight chain 3 (LC3B-II), a marker of autophagy, are also reduced in Ts1Cje hippocampus (Fig. 3A). Moreover, the levels of TOM20 (Translocase of Outer Mitochondrial membrane 20), a marker of mitochondrial mass, were increased in the Ts1Cje hippocampus (Fig. 3B).

Most important for the objectives of this work, we found that some key synaptic plasticity related pathways, including calcium signaling, CREB signaling, the endocannabinoid neuronal synapse pathway, the glutamate receptor signaling, and the synaptic LTD, were also significantly affected in Ts1Cje SNs (Fig. 2, Table 2 and Additional file 2: Table S6). In fact, the Z-score analysis of the data predicted increased activity of these pathways in Ts1Cje SNs (Additional file 2: Table S7).
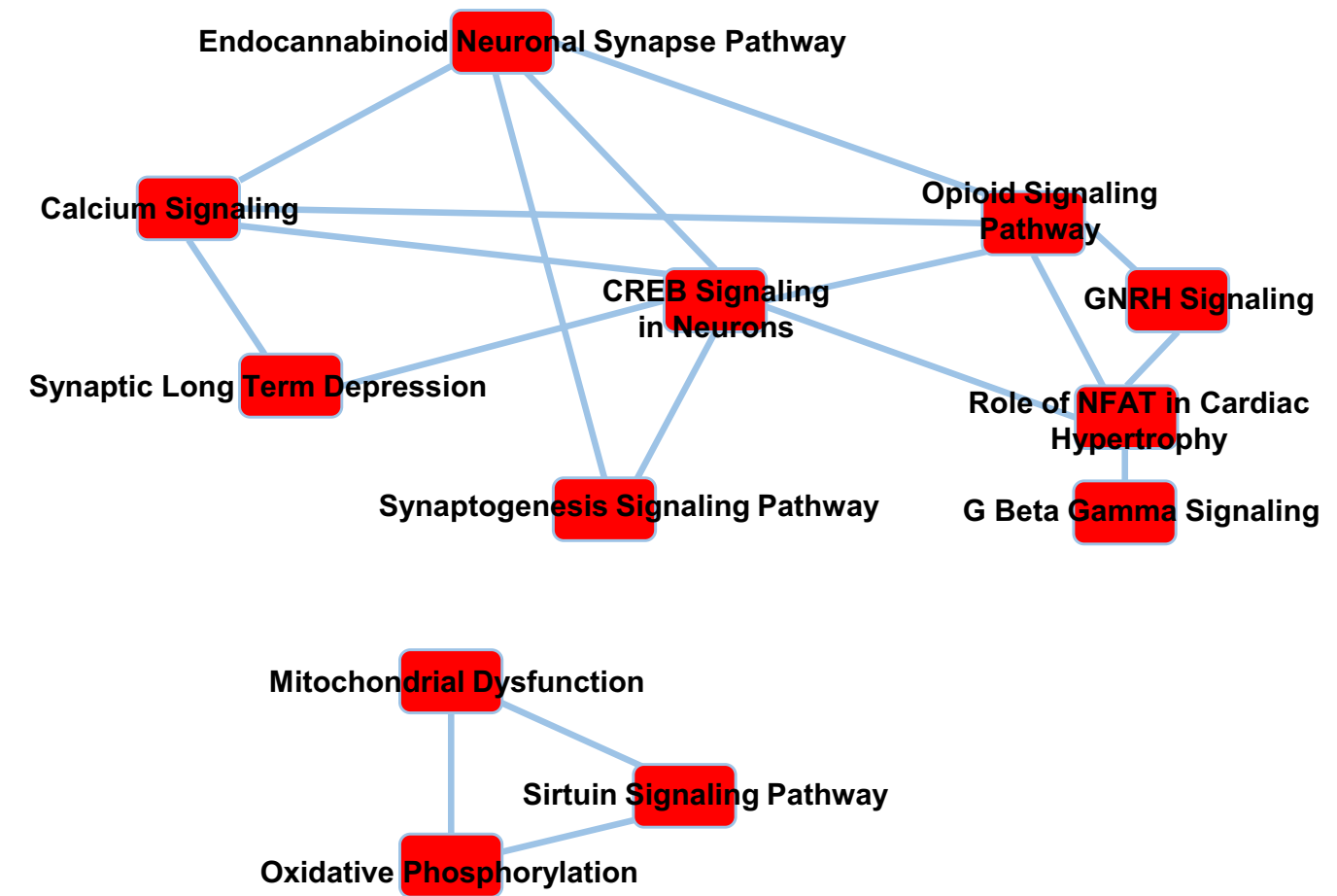

Fig. 2 Canonical IPA pathways affected in Ts1Cje SNs. The most significant canonical pathways identified by IPA among the altered proteins in Ts1Cje SNs are shown. Overlapping pathways sharing at least 7 proteins are connected by solid lines 
Table 1 Proteins involved in mitochondrial pathways affected in Ts1Cje SNs

\begin{tabular}{|c|c|c|c|c|}
\hline Symbol & Entrez gene name & ID & Ts1Cje & Pathway \\
\hline APP & Amyloid beta precursor protein & P12023 & 1.246 & $\begin{array}{l}\text { Mitochondrial dysfunction } \\
\text { Sirtuin signaling }\end{array}$ \\
\hline ATP5MF & ATP synthase membrane subunit $f$ & P56135 & 1.925 & $\begin{array}{l}\text { Mitochondrial dysfunction } \\
\text { Oxidative phosphorylation }\end{array}$ \\
\hline ATP5PD & ATP synthase peripheral stalk subunit d & Q9DCX2 & 1.523 & $\begin{array}{l}\text { Mitochondrial dysfunction } \\
\text { Oxidative phosphorylation }\end{array}$ \\
\hline ATP5PF & ATP synthase peripheral stalk subunit F6 & P97450 & 1.907 & $\begin{array}{l}\text { Mitochondrial dysfunction } \\
\text { Oxidative phosphorylation } \\
\text { Sirtuin signaling }\end{array}$ \\
\hline $\operatorname{cox} 411$ & Cytochrome c oxidase subunit 411 & P19783 & 1.818 & $\begin{array}{l}\text { Mitochondrial dysfunction } \\
\text { Oxidative phosphorylation }\end{array}$ \\
\hline $\operatorname{COX} 5 \mathrm{~A}$ & Cytochrome $c$ oxidase subunit 5A & P12787 & 1.889 & $\begin{array}{l}\text { Mitochondrial dysfunction } \\
\text { Oxidative phosphorylation }\end{array}$ \\
\hline Cox6c & Cytochrome $c$ oxidase subunit $6 \mathrm{C}$ & Q9CPQ1 & 2.119 & $\begin{array}{l}\text { Mitochondrial dysfunction } \\
\text { Oxidative phosphorylation }\end{array}$ \\
\hline CYC1 & Cytochrome $c 1$ & Q9D0M3 & 1.728 & $\begin{array}{l}\text { Mitochondrial dysfunction } \\
\text { Oxidative phosphorylation } \\
\text { Sirtuin signaling }\end{array}$ \\
\hline CYCS & Cytochrome c. somatic & P62897 & 1.976 & $\begin{array}{l}\text { Mitochondrial dysfunction } \\
\text { Oxidative phosphorylation }\end{array}$ \\
\hline GPD2 & Glycerol-3-phosphate dehydrogenase 2 & Q64521 & 1.549 & Mitochondrial dysfunction \\
\hline MAOB & Monoamine oxidase B & Q8BW75 & 1.235 & Mitochondrial dysfunction \\
\hline $\mathrm{MT}-\mathrm{CO} 2$ & Cytochrome c oxidase subunit II & P00405 & 2.804 & $\begin{array}{l}\text { Mitochondrial dysfunction } \\
\text { Oxidative phosphorylation }\end{array}$ \\
\hline NDUFA2 & NADH:ubiquinone oxidoreductase subunit A2 & Q9CQ75 & 1.337 & $\begin{array}{l}\text { Mitochondrial dysfunction } \\
\text { Oxidative phosphorylation } \\
\text { Sirtuin signaling }\end{array}$ \\
\hline NDUFA4 & NDUFA4 mitochondrial complex associated & Q62425 & 1.331 & $\begin{array}{l}\text { Mitochondrial dysfunction } \\
\text { Oxidative phosphorylation } \\
\text { Sirtuin signaling }\end{array}$ \\
\hline NDUFA8 & NADH:ubiquinone oxidoreductase subunit A8 & Q9DCJ5 & 1.546 & $\begin{array}{l}\text { Mitochondrial dysfunction } \\
\text { Oxidative phosphorylation } \\
\text { Sirtuin signaling }\end{array}$ \\
\hline NDUFAF1 & NADH:ubiquinone oxidoreductase complex assembly factor 1 & $\mathrm{~A} 2 \mathrm{AQ} 17$ & 1.359 & $\begin{array}{l}\text { Mitochondrial dysfunction } \\
\text { Sirtuin signaling }\end{array}$ \\
\hline NDUFS1 & NADH:ubiquinone oxidoreductase core subunit S1 & Q91VD9 & 1.813 & $\begin{array}{l}\text { Mitochondrial dysfunction } \\
\text { Oxidative phosphorylation } \\
\text { Sirtuin signaling }\end{array}$ \\
\hline NDUFS3 & NADH:ubiquinone oxidoreductase core subunit S3 & Q9DCT2 & 1.713 & $\begin{array}{l}\text { Mitochondrial dysfunction } \\
\text { Oxidative phosphorylation } \\
\text { Sirtuin signaling }\end{array}$ \\
\hline NDUFS6 & NADH:ubiquinone oxidoreductase subunit S6 & P52503 & 1.368 & $\begin{array}{l}\text { Mitochondrial dysfunction } \\
\text { Oxidative phosphorylation } \\
\text { Sirtuin signaling }\end{array}$ \\
\hline NDUFV2 & NADH:ubiquinone oxidoreductase core subunit V2 & Q9D6J6 & 1.487 & $\begin{array}{l}\text { Mitochondrial dysfunction } \\
\text { Oxidative phosphorylation } \\
\text { Sirtuin signaling }\end{array}$ \\
\hline SLC25A4 & Solute carrier family 25 member 4 & P48962 & 1.591 & Sirtuin signaling \\
\hline UQCRB & Ubiquinol-cytochrome $c$ reductase binding protein & Q9CQB4 & 1.928 & $\begin{array}{l}\text { Mitochondrial dysfunction } \\
\text { Oxidative phosphorylation }\end{array}$ \\
\hline UQCRC1 & Ubiquinol-cytochrome $\mathrm{c}$ reductase core protein 1 & Q9CZ13 & 1.687 & $\begin{array}{l}\text { Mitochondrial dysfunction } \\
\text { Oxidative phosphorylation }\end{array}$ \\
\hline UQCRFS1 & Ubiquinol-cytochrome c reductase. Rieske iron-sulfur polypeptide 1 & Q9CR68 & 3.192 & $\begin{array}{l}\text { Mitochondrial dysfunction } \\
\text { Oxidative phosphorylation } \\
\text { Sirtuin signaling }\end{array}$ \\
\hline
\end{tabular}


Table 1 (continued)

\begin{tabular}{|c|c|c|c|c|}
\hline Symbol & Entrez gene name & ID & Ts1Cje & Pathway \\
\hline$\overline{\text { UQCRQ }}$ & Ubiquinol-cytochrome $\mathrm{c}$ reductase complex III subunit VII & Q9CQ69 & 2.522 & $\begin{array}{l}\text { Mitochondrial dysfunction } \\
\text { Oxidative phosphorylation }\end{array}$ \\
\hline VDAC1 & Voltage dependent anion channel 1 & Q60932 & 1.762 & $\begin{array}{l}\text { Mitochondrial dysfunction } \\
\text { Sirtuin signaling }\end{array}$ \\
\hline VDAC2 & Voltage dependent anion channel 2 & Q60930 & 2.043 & $\begin{array}{l}\text { Mitochondrial dysfunction } \\
\text { Sirtuin signaling }\end{array}$ \\
\hline WRN & Werner syndrome RecQ like helicase & O09053 & -1.341 & Sirtuin signaling \\
\hline
\end{tabular}

The relative amounts (fold change, compared to WT SNs) of these proteins in Ts1Cje SNs are shown

a
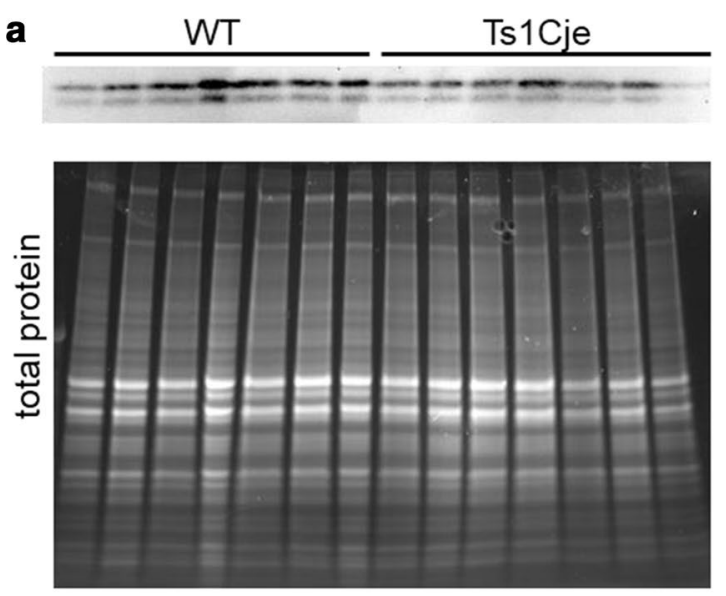

b
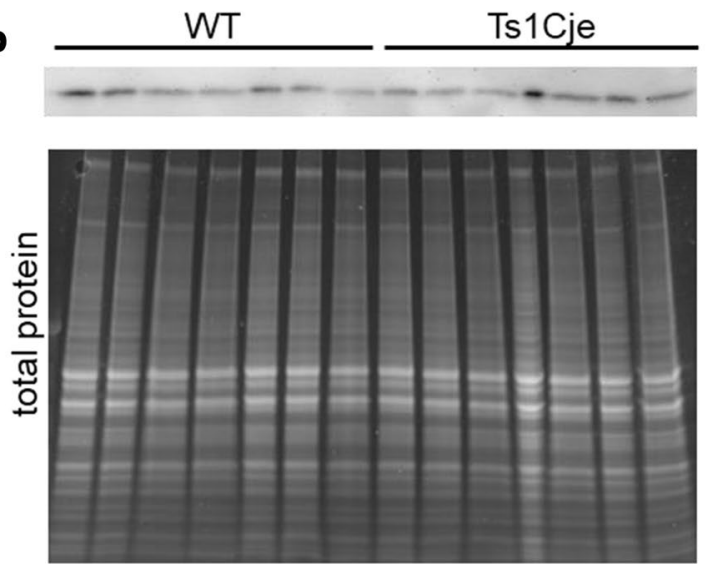

\section{LC3B-I}

LC3B-II

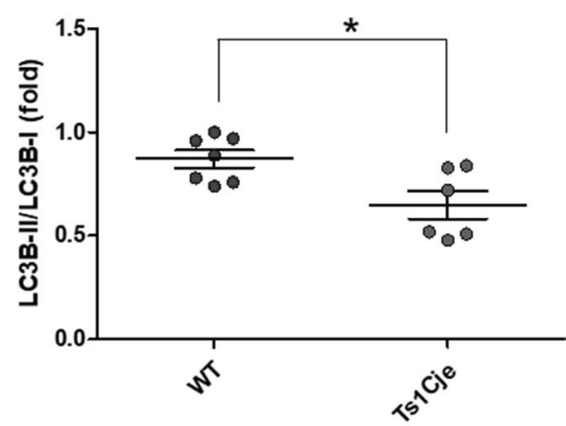

\section{TOM20}

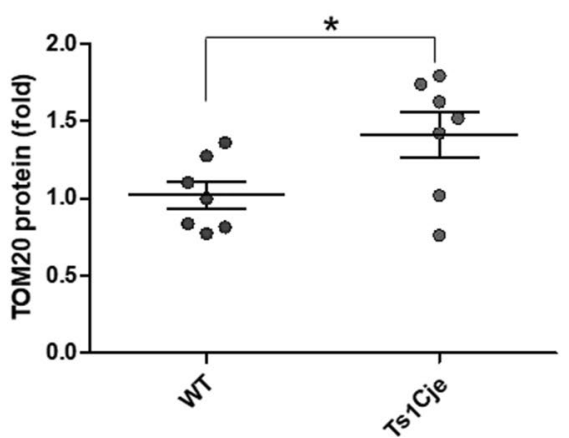

Fig. 3 Quantification of LC3B-II and TOM20 proteins in WT and Ts1Cje hippocampus. Hippocampal proteins from WT and Ts1Cje mice pairs were analyzed in Western blot with anti-LC3B or anti-TOM20 antibody. A LC3B western blot showing WT and Ts1Cje littermate pairs analyzed and total protein loaded. The ratio LC3B-II/LC3B-I is shown as the mean \pm SEM (WT: 0.8714 $\pm 0.04154 ;$ Ts 1 Cje: $0.6500 \pm 0.06802 ; p=0.0152$, Student's t-test, $\mathrm{n}=7$ for WT and $\mathrm{n}=6$ for Ts 1Cje). B TOM20 western blot showing WT and Ts1Cje littermate pairs analyzed and total protein loaded. The signals were normalized to the corresponding total protein loaded and the mean \pm SEM values are shown (WT: 1.024 $\pm 0.08799 ;$ Ts1Cje: 1.412 \pm 0.1452 ; $p=0.0414$, Student's t-test, $n=7$ animals per genotype) 
Table 2 Proteins involved in synaptic plasticity pathways affected in Ts1Cje SNs

\begin{tabular}{|c|c|c|c|c|}
\hline Symbol & Entrez gene name & ID & Ts1Cje & Pathway \\
\hline ADCY9 & Adenylate cyclase 9 & P51830 & 1.344 & $\begin{array}{l}\text { CREB signaling } \\
\text { Endocannabinoid neuronal synapse }\end{array}$ \\
\hline ATP2A2 & $\begin{array}{l}\text { ATPase sarcoplasmic/endoplasmic reticulum Ca2+ } \\
\text { transporting } 2\end{array}$ & O55143 & 1.251 & Calcium signaling \\
\hline ATP2B1 & ATPase plasma membrane $\mathrm{Ca} 2+$ transporting 1 & G5E829 & 1.329 & Calcium signaling \\
\hline ATP2B2 & ATPase plasma membrane $\mathrm{Ca} 2+$ transporting 2 & F8WHB1 & 1.268 & Calcium signaling \\
\hline CACNA1A & Calcium voltage-gated channel subunit alpha1 A & P97445 & 1.314 & $\begin{array}{l}\text { Calcium signaling } \\
\text { CREB signaling } \\
\text { Endocannabinoid neuronal synapse } \\
\text { Synaptic LTD }\end{array}$ \\
\hline CACNA1G & Calcium voltage-gated channel subunit alpha $1 \mathrm{G}$ & Q5SUF8 & 1.474 & $\begin{array}{l}\text { Calcium signaling } \\
\text { CREB signaling } \\
\text { Endocannabinoid neuronal synapse } \\
\text { Synaptic LTD }\end{array}$ \\
\hline CACNA2D1 & $\begin{array}{l}\text { Calcium voltage-gated channel auxiliary subunit } \\
\text { alpha2delta } 1\end{array}$ & 008532 & 1.262 & $\begin{array}{l}\text { Calcium signaling } \\
\text { CREB signaling } \\
\text { Endocannabinoid neuronal synapse } \\
\text { Synaptic LTD }\end{array}$ \\
\hline GNB2 & G protein subunit beta 2 & E9QKR0 & 1.207 & CREB signaling \\
\hline GNG2 & G protein subunit gamma 2 & P63213 & -1.212 & $\begin{array}{l}\text { CREB signaling } \\
\text { Endocannabinoid neuronal synapse Glutamate receptor } \\
\text { signaling }\end{array}$ \\
\hline GRIA2 & Glutamate ionotropic receptor AMPA type subunit 2 & P23819 & 1.481 & $\begin{array}{l}\text { Calcium signaling } \\
\text { CREB signaling } \\
\text { Endocannabinoid neuronal synapse Glutamate receptor } \\
\text { signaling } \\
\text { Synaptic LTD }\end{array}$ \\
\hline GRIA4 & Glutamate ionotropic receptor AMPA type subunit 4 & Q9Z2W8 & -1.251 & $\begin{array}{l}\text { Calcium signaling } \\
\text { CREB signaling } \\
\text { Endocannabinoid neuronal synapse } \\
\text { Glutamate receptor signaling } \\
\text { Synaptic LTD }\end{array}$ \\
\hline GRIN1 & Glutamate ionotropic receptor NMDA type subunit 1 & A2Al21 & 1.758 & $\begin{array}{l}\text { Calcium signaling } \\
\text { CREB signaling } \\
\text { Endocannabinoid neuronal synapse Glutamate receptor } \\
\text { signaling }\end{array}$ \\
\hline GRIN2B & Glutamate ionotropic receptor NMDA type subunit 2B & Q01097 & 1.371 & $\begin{array}{l}\text { Calcium signaling } \\
\text { CREB signaling } \\
\text { Endocannabinoid neuronal synapse } \\
\text { Glutamate receptor signaling }\end{array}$ \\
\hline GRM5 & Glutamate metabotropic receptor 5 & Q3UVX5 & 1.200 & $\begin{array}{l}\text { CREB signaling } \\
\text { Endocannabinoid neuronal synapse } \\
\text { Glutamate receptor signaling } \\
\text { Synaptic LTD }\end{array}$ \\
\hline RAP2B & RAP2B. member of RAS oncogene family & P61226 & 1.300 & $\begin{array}{l}\text { Calcium signaling } \\
\text { CREB signaling } \\
\text { Synaptic LTD }\end{array}$ \\
\hline RYR2 & Ryanodine receptor 2 & E9Q401 & 1.251 & $\begin{array}{l}\text { Calcium signaling } \\
\text { Synaptic LTD }\end{array}$ \\
\hline
\end{tabular}

The relative amounts (fold change, compared to WT SNs) of these proteins in Ts1Cje SNs are shown

\section{mGluR-LTD is enhanced in the CA1 region of Ts1Cje hippocampus}

As mentioned above, the IPA analysis suggested that LTD is increased in the Ts1Cje hippocampus. It is well known that mTOR is involved in this type of plasticity $[10,12]$ and, remarkably, mTOR is hyperactivated in Ts1Cje hippocampus [3]. These data stimulated us to evaluate mGluR-LTD in Ts1Cje mice.

mGluR-LTD is experimentally induced in hippocampal slices by a brief ( $5 \mathrm{~min}$ ) exposure to DHPG, a specific agonist of mGluR1/5 receptors [8]. As expected, an LTD of evoked excitatory synaptic responses was evident in 


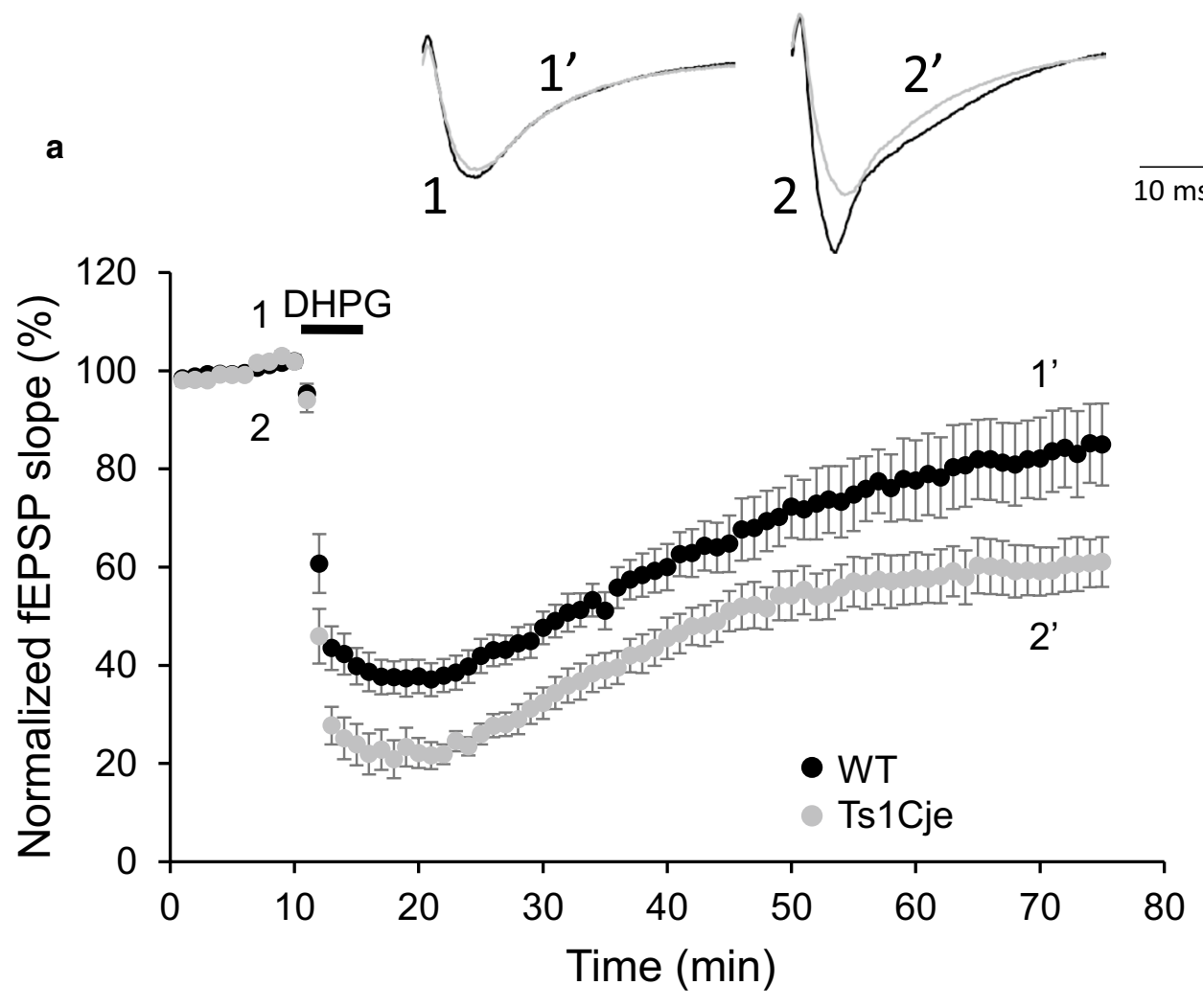

b

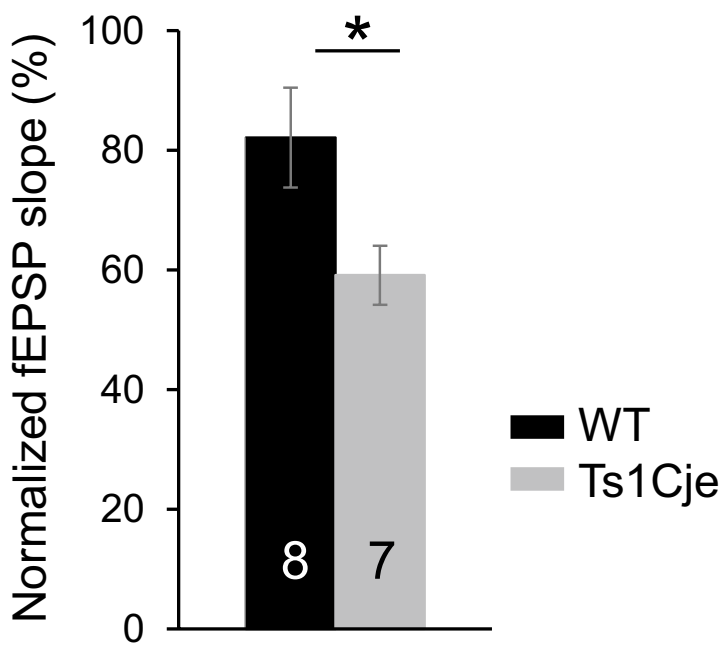

Fig. 4 mGluR-LTD in WT and Ts1Cje hippocampal slices. A Time course of DHPG effects on field excitatory postsynaptic potentials (fEPSP) in WT and Ts 1Cje mice. Upper insets: representative traces of a fEPSP before $(1,2)$ and after $\left(1^{\prime}, 2\right)$ DHPG application in WT $(1,1)$ and Ts 1 Cje $(2,2)$ mice. The mean fEPSP slopes before DHPG perfusion between WT and Ts1Cje mice were not different. B Quantification of the effects depicted in $\mathbf{A}$. The error bars represent the SEM. The number of slices for each condition is indicated in the corresponding bar (WT: 8 slices from 4 mice; TS1Cje: 7 slices from 3 mice). $p=0.039$ Student's t-test 

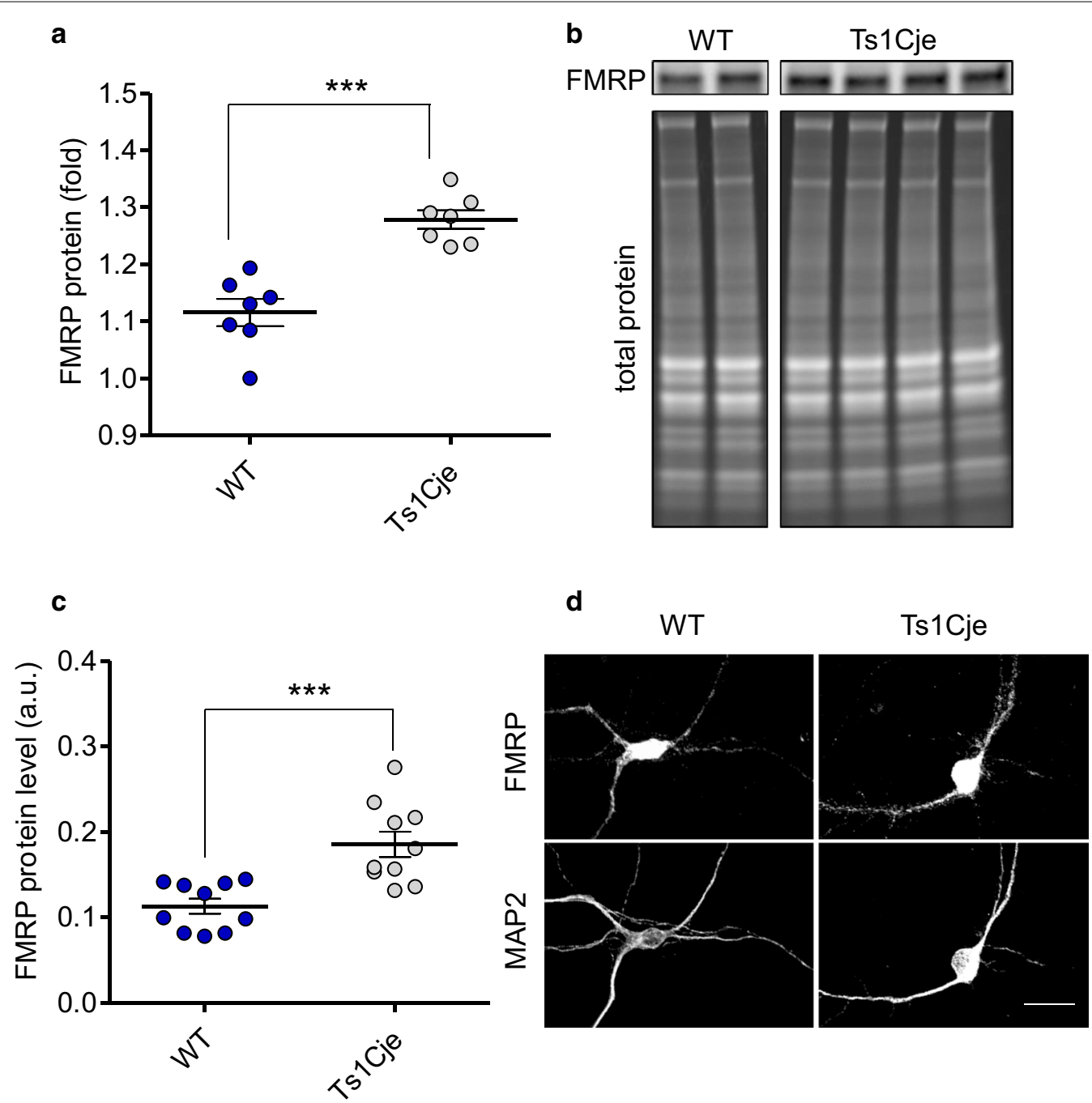

Fig. 5 Quantification of FMRP protein in WT and Ts1Cje hippocampus. A Hippocampal proteins from WT and Ts1Cje mice pairs were analyzed by Western blots with an anti-FMRP antibody. The signals were normalized to the corresponding total protein loaded and the mean \pm SEM values are shown (WT: 1.115 $\pm 0.0239 ;$ Ts 1 Cje: $1.278 \pm 0.0162 ; \mathrm{p}=0.0006$, Mann Whitney test, $\mathrm{n}=7$ animals per genotype). $\mathbf{B}$ Representative Western blot showing two WT and four Ts1Cje littermate pairs (some lanes corresponding to non-littermate animals have been removed, but both WT and Ts1Cje panels correspond to the same Western blot experiment). C Quantification of the relative amount of FMRP protein in dendrites of WT and Ts1Cje hippocampal neurons at DIV14. The mean pixel intensity \pm SEM for FMRP immunofluorescence in dendrites is shown in arbitrary units (a.u.) $(p=0.0006$, $t$ test, $n=10$ images per genotype; each image typically contained one neuron). $\mathbf{D}$ Representative gray scale confocal images from the experiment in C, showing FMRP and MAP2 labeling in WT and Ts1Cje neurons. Scale bar $=20 \mu \mathrm{m}$. Note that dendritic branching and length are reduced in Ts1Cje neurons, compared to WT controls (unpublished observations)

WT slices after DHPG exposure (Fig. 4, 82.12 $\pm 8.31 \%$ of baseline, $\mathrm{n}=8$ slices from 4 mice). Remarkably, an enhanced mGluR-LTD was elicited in Ts1Cje hippocampal slices (Fig. 4, $59.12 \pm 4.92 \%$ of baseline, $\mathrm{n}=7$ slices from 3 mice). In conclusion, we found that mGluR-LTD was exaggerated in the Ts1Cje CA1 hippocampal region.

Enhanced mGluR-LTD is a hallmark of FMR1 knockout mice [27]. As already mentioned, FMRP (the FMR1 encoded protein) is a repressor of local synthesis of proteins necessary for mGluR-LTD [28-30]. Thus, we evaluated the amounts of FMRP in Ts1Cje hippocampus by Western blot and, strikingly, we found a slight, yet significant, increase of FMRP (Fig. 5). To evaluate more precisely the amount FMRP in the dendritic compartment, we performed double immunocytochemistry in primary cultures of hippocampal neurons at DIV 14 and measured the fluorescence level of FMRP labeling in MAP2positive neurites (i.e., dendrites). As shown in Fig. 5, dendritic FMRP labeling was 1.6-fold higher in Ts1Cje neurons than in those from the WT. Hence, we must 
Table 3 Dendritic spine morphology comparison

\begin{tabular}{|c|c|c|c|c|}
\hline Spine morphology & WT $(n=248)$ & Ts1Cje $(n=151)$ & WT RAPA $(n=143)$ & $\begin{array}{l}\text { Ts1Cje } \\
\text { RAPA } \\
(n=635)\end{array}$ \\
\hline Filopodium & 14.9 & 13.2 & 22.4 & 19.7 \\
\hline Stubby & 27.8 & 29.8 & 25.2 & 26.5 \\
\hline Mushroom & 57.3 & 57.0 & 52.4 & 53.9 \\
\hline
\end{tabular}

The percentages of filopodia, stubby and mushroom spines present in secondary dendrites of apical stratum radiatum CA1 neurons in WT, Ts1Cje, and prenatally rapamycin-treated WT and Ts1Cje mice are indicated. Number of mice used per condition was 2, except for WT RAPA (a single animal). Total number of spines ( $\mathrm{n}$ ) is also indicated for each experimental group

conclude that despite the higher levels of FMRP, mGluRLTD was abnormally enhanced in Ts1Cje hippocampus.

\section{Prenatal treatment with rapamycin normalizes size distribution of mushroom type dendritic spines in the stratum radiatum of $\mathrm{Ts} 1 \mathrm{Cje}$ mice}

It has been proposed that LTD is a physiological correlate of spine shrinkage [13, 31,32]. Since dendritic spine alterations have been described in DS and DS mouse models including Ts1Cje [33-35], we decided to evaluate the effect of prenatal treatment with rapamycin on dendritic spine density in postnatal Ts1Cje mice using a rapid Golgi stain method (see "Materials and methods"). We observed a reduced spine density in secondary dendrites of CA1 stratum radiatum of untreated Ts1Cje animals, compared to WT controls (WT: $0.640 \pm 0.031$ spines $/ \mu \mathrm{m}$, $\mathrm{n}=50$; Ts1Cje: $0.523 \pm 0.035$ spines $/ \mu \mathrm{m}, \mathrm{n}=26$; $\mathrm{t}$-Student test $\mathrm{p}$-value $=0.015$ ). However, prenatal treatment with rapamycin produced no significant effect on spine density in either group (WT RAPA: $0.666 \pm 0.029$ spines $/ \mu \mathrm{m}$, $\mathrm{n}=27$; Ts1Cje RAPA: $0.572 \pm 0.021$ spines $/ \mu \mathrm{m}, \mathrm{n}=31$ ).

It has been shown that the CA1 spines susceptible to undergo mGluR-LTD are large-head mushroom spines that contain endoplasmic reticulum (ER) and often harbor a spine apparatus, whereas spines without ER are refractory to this plasticity [36]. Thus, we decided to assess the proportion of filopodia, stubby and mushroom shape spines but we found no significant differences in the proportion of the different morphology categories among the experimental groups (Table 3). Howewer, we found that the proportion of $0.5-0.7 \mu \mathrm{m}$ mushroom spines was significantly reduced in Ts1Cje animals, compared to WT, and recovered in Ts1Cje RAPA mice, whereas the percentage of $0.7-0.9 \mu \mathrm{m}$ mushroom spines was significantly increased in Ts1Cje mice and restored in Ts1Cje RAPA animals (Fig. 6 and Additional file 3: Table S8). Thus, prenatal treatment with rapamycin normalizes the size distribution of mushroom type dendritic spines in Ts1Cje stratum radiatum neurons.

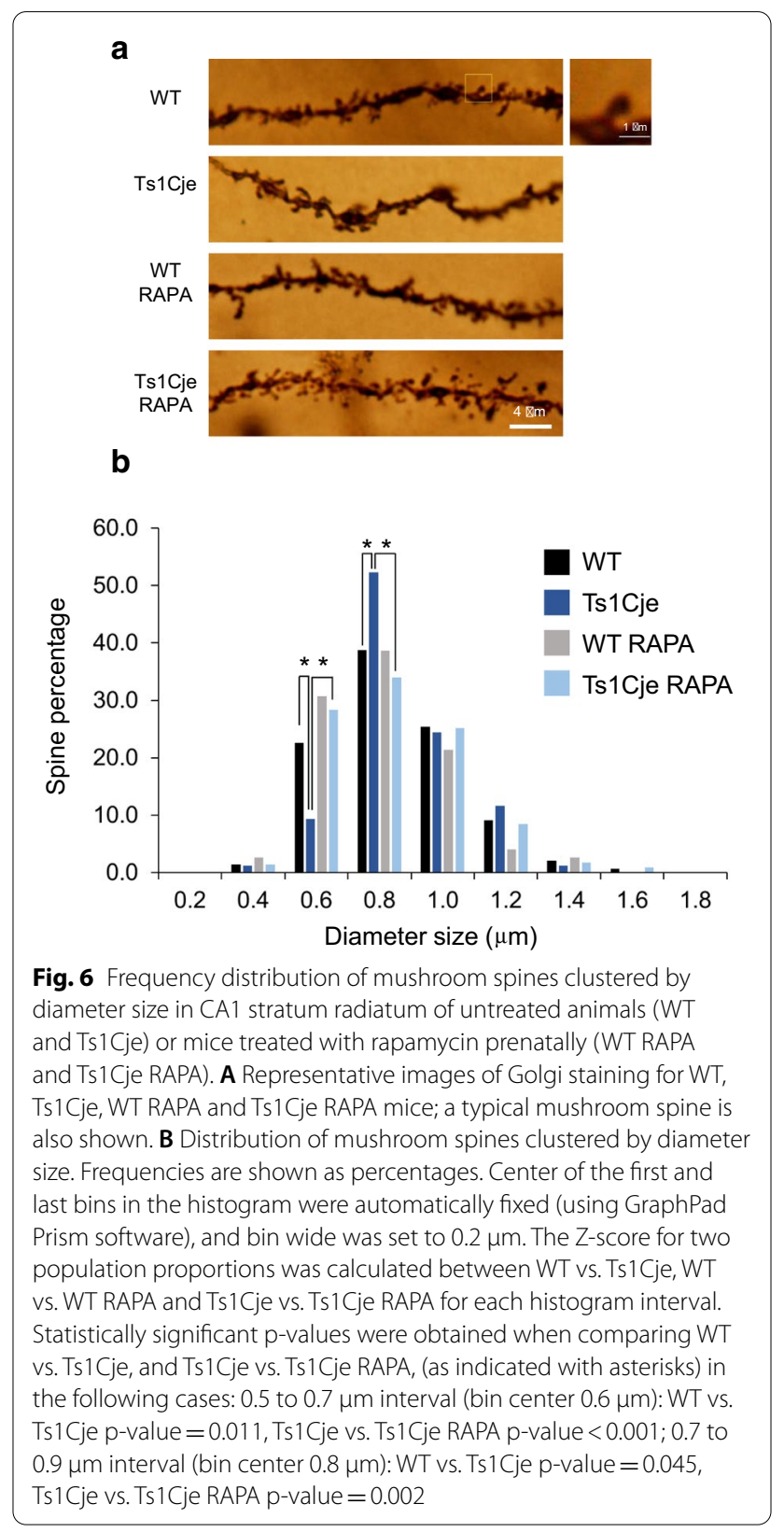




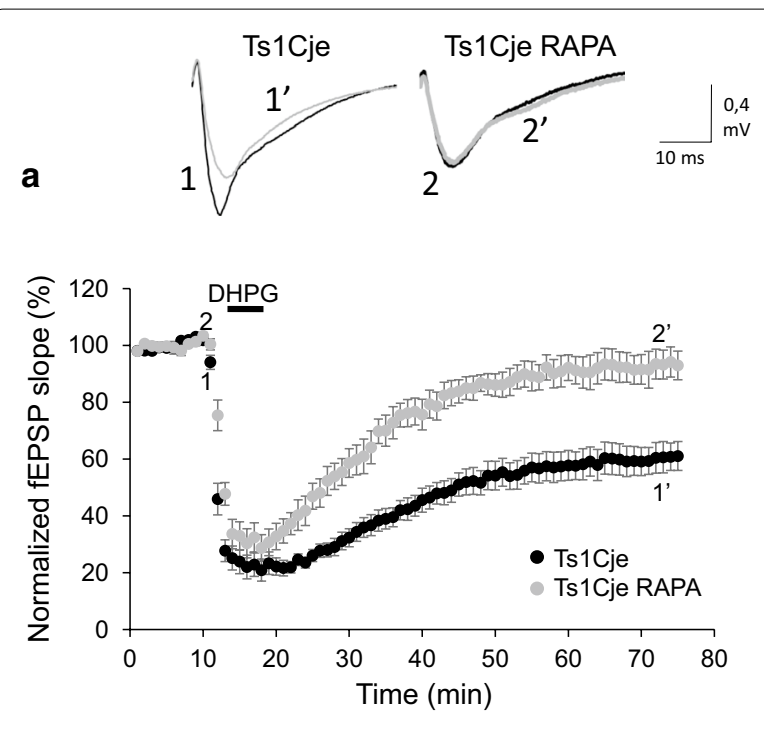

b

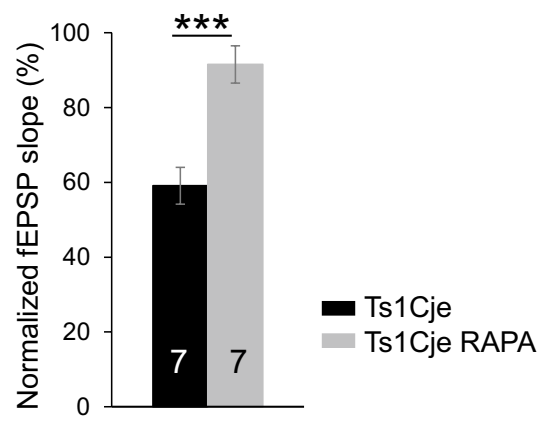

Fig. 7 mGluR-LTD in hippocampal slices of Ts1Cje mice treated with rapamycin prenatally. A Time course of DHPG effects on field excitatory postsynaptic potentials (fEPSP) in Ts1Cje mice treated with rapamycin prenatally (Ts1Cje RAPA) and control Ts 1Cje mice (same data as in Fig. 4). Upper insets: representative traces of a fEPSP before $(1,2)$ and after $(1,2)$ DHPG application in Ts1 Cje $\left(1,1^{\prime}\right.$; same data as in Fig. 4) and Ts1Cje RAPA $(2,2)$ mice. The mean fEPSP slopes before DHPG perfusion between Ts1Cje and Ts1Cje RAPA mice were not different. B Quantification of the effects depicted in $\mathbf{A}$. The error bars represent the SEM. The number of slices for each condition is indicated in the corresponding bar (Ts1 Cje: 7 slices from 3 mice; Ts1Cje RAPA: 7 slices from 4 mice). $p<0.001$ Student's t-test

\section{Prenatal treatment with rapamycin reduces mGluR-LTD in Ts1Cje hippocampus}

In order to determine if the normalization of mushroom spine size distribution observed in Ts1Cje treated prenatally with rapamycin (Fig. 6) correlated with an effect on mGluR-LTD, we evaluated this plasticity in hippocampal slices of postnatal Ts1Cje mice treated prenatally with rapamycin (see "Materials and methods"). Remarkably, as shown in Fig. 7, mGluR-LTD was reduced in Ts1Cje RAPA mice $(91.55 \pm 5.23 \%$ of baseline, $\mathrm{n}=7$ slices from 4 mice) compared to Ts1Cje, and showed values similar to those of WT.

\section{Discussion}

We have previously shown that the mTOR pathway is hyperactivated in Ts1Cje hippocampus [3]. Afterwards, other groups reported mTOR hyperactivation in postmortem DS brain $[4,5]$. We have also found that rapamycin restored both BDNF-LTP and the persistence of LTM in the Barnes maze [7].

We have here presented the characterization of the Ts1Cje hippocampal synaptic proteome, and we have identified several affected pathways that could account for plasticity and/or memory deficits of Ts1Cje mice. Two main functions were predicted to be altered in Ts1Cje hippocampus: mitochondrial function and synaptic plasticity (including LTD).

Mitochondrial dysfunction and increased oxidative stress have been previously found in the Ts1Cje brain [37]. In fact, altered mitochondrial function has long been associated with DS [23-25]. It has been recently found damaged mitochondria linked to increased oxidative stress, reduced mitophagy and reduced autophagy, together with mTOR hyperactivation in fibroblasts from DS patients [26]. The role of mTORC1 as regulator of both general autophagy and mitophagy induction after oxidative phosphorylation uncoupling is well established [38]. Accordingly, pharmacological inhibition of mTOR using AZD8055, which inhibits both mTORC1 and mTORC2 [39], restored autophagy and mitophagy in DS fibroblasts [26]. As mentioned before, we previously demonstrated hyperactivation of mTOR in the Ts1Cje hippocampus [3]. Accordingly, we have here observed that autophagy is reduced, which could be related to the mitochondrial dysfunction that we detected in the proteomic analysis of Ts1Cje SNs, and to the increased levels of the mitochondrial mass marker TOM20 we measured in Ts1Cje adult hippocampus (Fig. 3).

Regarding synaptic plasticity, we found that mGluRLTD is enhanced in Ts1Cje hippocampus. Many forms of synaptic plasticity have been characterized in the Ts1Cje and other DS mouse models [7, 35, 40]. mGluR-LTD has been previously studied in the Ts65Dn model but, in contrast to our results, a normal hippocampal mGluR-LTD, compared to WT, was found [41]. Nevertheless, there are important differences between the Ts65Dn and Ts1Cje models that could explain this apparent contradiction. Thus, additional DS non-related trisomic genes exist in Ts65Dn [42]. The fact that 6-8 month-old mice were used in the Scott-McKean and Costa study while we used P21-30 mice could also explain the different results since the mechanisms of mGluR-LTD seem to be developmentally regulated [43]. 
mGluR-LTD is triggered by activation of group I mGluR (i.e., mGluR1/5) and relies on protein translation [8]. Two main signaling cascades that regulate protein synthesis are engaged following mGluR1/5 stimulation: mTOR and ERK. Both pathways can stimulate cap-dependent translation at the initiation level. The relative contribution of these cascades to the protein synthesis necessary for mGluR-LTD is nevertheless unclear (for a review see [16]). Interestingly, it has been recently shown that mTORC2, but not mTORC1, is required for mGluR-LTD [12]. mTORC2 regulates actin cytoskeleton and, in fact, actin polymerization-depolymerization inhibition abolishes mGluR-LTD [13]. In any case, it seems clear that in wild-type conditions, rapid synthesis and degradation of FMRP is necessary for mGluR-LTD [17], which leads to transient local translation of key proteins involved in AMPAR internalization (i.e. GluA1 endocytosis), such as Arc/Arg3.1 [28, 30, 44]. Thus, after mGluR1/5 stimulation, FMRP is rapidly ( $<1 \mathrm{~min})$ dephosphorylated by protein phosphatase $2 \mathrm{~A}$, and then (1-5 $\mathrm{min}$ ) re-phosphorylated by p70S6K [45], a kinase that belongs to the mTOR pathway. Dephosphorylated FMRP is associated with polyribosomes, and phosphorylated FMRP with stalled (non-translating) ribosomes [46]. Thus, the short period after mGluR1/5 in which FMPR is dephosphorylated permits the translation of the FMRP-regulated proteins involved in mGluR-LTD [45].

Remarkably, and similarly to our results in Ts1Cje mice, it is well established that mGluR-LTD is exaggerated in FMRP knockout (KO) mice [27], a model for Fragile X. However, Fragile $\mathrm{X}$ is due to loss of expression of FMRP and, in contrast, we found higher levels of FMPR in the Ts1Cje hippocampus, strongly suggesting a different cause for the enhanced hippocampal mGluR-LTD in trisomic mice. From the list of proteomic changes involved in LTD identified in Ts1Cje SNs, the increased level of mGluR5 (indicated as GMR5 in Table 2) is of particular interest, since it is the main receptor that mediates mGluR-LTD. Thus, the 1.2-fold increase of mGluR5 in Ts1Cje SNs we detected could collaborate to the exaggerated mGluR-LTD we observed. On the other hand, it has been shown that the spines susceptible to undergo mGluR-LTD in the CA1 constitute a particular subpopulation of large-head mushroom spines with ER and spine apparatus, whereas spines without ER are refractory to mGluR-LTD [36]. We have here shown that the percentage of mushroom spines with a $0.7-0.9 \mu \mathrm{m}$ size was notably increased in Ts1Cje CA1 dendrites, compared to WT (Fig. 5). Although we are not sure if this subpopulation corresponds to that described in ref. [36], it is tempting to speculate that exaggerated mGluR-LTD in Ts1Cje hippocampus could be due to a higher proportion of ERcontaining spines, susceptible to undergo mGluR-LTD.
Excitingly, rapamycin treatment of pregnant dams normalized the referred mushroom spine phenotype and reduced the mGluR-LTD in the Ts1Cje offspring.

mGluR stimulation leads to local inositol trisphosphate (IP3) receptor activation and calcium release from the ER [36]. Moreover, ryanodine receptors (RyRs) are particularly abundant in the spine apparatus [47], an ER membrane specialization of stacked discs, which plays roles in local translation and calcium signaling [48]. mGluR-LTD induces trafficking from the ER to the synapse of GluA2, an AMPAR subunit that renders the receptor impermeable to calcium. This trafficking depends on IP3 and RyR-mediated calcium release, and translation [49, 50]. Interestingly, IPA of the Ts1Cje hippocampal SNs proteomic data predicted increased calcium signaling due to higher levels of RyR2, glutamate receptor subunits (including GluA2, GluA4, GluN1, GluN2B), plasma membrane calcium ATPases, and calcium voltage-gated channel subunits (Table 2). We think that the increased levels of these proteins could be a consequence of the higher percentage of the 0.7-0.9 $\mu \mathrm{m}$ mushroom spines in Ts1Cje hippocampus. Interestingly, the morphology of dendritic spines appeared among the functions that IPA predicted to be affected in Ts1Cje (not shown), based on the altered expression of several proteins, including catenin alpha 2 (CTNNA2). Remarkably, it has been shown that the mutation of CTNNA2 induces spine elongation in hippocampal neurons [51]. Conversely, we hypothesize that the higher level of CTNNA2 we found in Ts1Cje SNs (Additional File 2: Table S5) could provoke spine enlargement. Nevertheless, it should be noted that adult animals were used for proteomics while juvenile mice were used for electrophysiology experiments and spine morphology assessment. Thus, these correlations should be taken with precaution.

In summary, the molecular mechanism behind the mushroom spine morphologic phenotype in Ts1Cje hippocampal dendrites is unknown. Nevertheless, since it is recovered by rapamycin, mTOR signaling should be involved. We have previously found increased levels of both phospho-S6 (Ser235/236), a redout of mTORC1, and phospho-Akt (Ser473), a redout of mTORC2, in dendrites of Ts1Cje hippocampal neurons [3]. Accordingly, either mTORC1 or mTORC2 (or both) could be involved. Interestingly, RICTOR, a canonical component of mTORC2, interacts with Tiam1, a Rac-1 specific guanine nucleotide exchange factor, to regulate actin polymerization [52]. Tiam1 is encoded in the human chromosome 21 and it is in trisomy in Ts1Cje mice. Thus, Tiam 1 overexpression in addition to mTORC2 hyperactivation could be relevant for the spine phenotype.

In conclusion, we have here shown abnormal, exaggerated hippocampal mGluR-LTD in Ts1Cje mice, which correlates with an increased proportion of $0.7-0.9 \mu \mathrm{m}$ mushroom spines in CA1 dendrites. Although the 
precise molecular/cellular mechanisms for these phenotypes remain to be elucidated, prenatal treatment with rapamycin restored both morphologic and functional phenotypes, highlighting the therapeutic potential of rapamycin/rapalogs for correcting synaptic defaults in DS.

\section{Abbreviations}

ACSFs: Artificial cerebrospinal fluid with partial substitution of Na with sucrose; AMPAR: AMPA receptor; Arc/Arg3.1: Activity Regulated Cytoskeleton-associated protein; a.u.: Arbitrary units; BDNF: Brain Derived Neurotrophic Factor; CTNNA2: Catenin alpha 2; DHPG: (S)-3,5-Dihydroxyphenylglycine; DIV: Days in vitro; DS: Down syndrome; ER: Endoplasmic reticulum; ERK: Extracellular signal-regulated kinase; FDR: False Discovery Rate; fEPSP: Field excitatory postsynaptic potential; FMRP: Fragile X mental retardation protein; IP: Inositol trisphosphate; IPA: Ingenuity Pathway Analysis; iTRAQ: Isobaric tag for relative and absolute quantitation; KO: Knockout; LC3B-II: Microtubule-associated protein 1A/1B-light chain 3; LTD: Long term depression; LTM: Long-term memory; LTP: Long-Term Potentiation; MAP1B: Microtubule Associated Protein 1B; mGluRLTD: Metabotropic Glutamate Receptor-Long Term Depression; MMU: Murine chromosome; mTOR: Mammalian target of rapamycin; N/A: Not applicable; NEO: Neomycine; OPHN1: Oligophrenin-1; P: Postnatal day; PANTHER: Protein Analysis Through Evolutionary Relationships; PBS: Phosphate-buffered saline; PFA: Paraformaldehyde; PVDF: Polyvinylidene difluoride; RAPTOR: Regulatory Associated Protein of mTOR; RICTOR: Rapamycin-Insensitive Companion of TOR; RRID: Research Resource Identifier; RT: Room temperature; RyRs: Ryanodine receptors; SEM: Standard error of the mean; SNs: Synaptoneurosomes; STEP: Striatal-Enriched Protein Phosphatase; TOM20: Translocase of Outer Mitochondrial membrane 20; WT: Wild-type.

\section{Supplementary Information}

The online version contains supplementary material available at https://doi. org/10.1186/s13041-021-00795-6.

Additional file 1: Table $\mathbf{S 1}$. List of proteins detected by tandem mass spectrometry iTRAQ in technical duplicates of WT and Ts1Cje synaptoneurosomes (SNs). Quantification is referred to one of the WT samples. Table S2. Same data as in Table S1 after elimination of proteins identified by only one unique peptide. Table $\mathbf{S 3}$. Geometric mean of the relative protein amount in Ts1Cje SNs, after elimination from Table S2 of proteins not detected in all the samples, as well as technical replicates with CV\% > 30\%. Table S4. Complete hierarchy of PANTHER Go-Slim Cellular Component proteins overrepresented and underrepresented in WT and Ts1Cje SNs.

Additional file 2: Table S5. List of proteins affected in Ts1Cje SNs. Table S6. List of canonical pathways affected in Ts1Cje SNs. Table S7. Z-score analysis of canonical pathways in Ts1Cje SNs.

Additional file 3: Table S8. Number of spines belonging to each category (size) included in Fig. 6.

\section{Acknowledgements}

We thank Mariló Pastor (IBiS Proteomics Service; Instituto de Biomedicina de Sevilla, Spain) for technical help and advice, the Supercomputing and Bioinnovation Center (Universidad de Málaga, Spain) for providing us with access to the IPA tool, and Francisco J. Tejedor for critically reading the manuscript.

\section{Authors' contributions}

JDU performed, analysed and designed electrophysiologic experiments, performed spine morphology analysis and western blot experiments, and isolated synaptoneurosomes for proteomics. JJC performed and analysed western blot and immunocytochemistry experiments, and isolated synaptoneurosomes for proteomics. IB performed western blot and helped with rapamycin treatments and Golgi staining. MLM designed research, performed and analysed western blot experiments, analysed proteomic data and wrote the paper. All authors read and approved the final manuscript.

\section{Funding}

This work was funded by the Junta de Andalucía (Spain, Grant P12-CTS-1818), the Ministerio de Economía, Industria y Competitividad (Spain, Grant:

SAF2015-65032-R), the Fondo Europeo de Desarrollo Regional (FEDER) and the Fondation Jérôme Lejeune (France).

\section{Availability of data and materials}

All data generated or analysed during this study are included in this published article and its additional information files. A preprint of this manuscript, including datasets, is available at: https://doi.org/10.1101/2020.04.08.032029.

\section{Declarations}

\section{Ethics approval and consent to participate}

Not applicable.

\section{Consent for publication}

Not applicable.

\section{Competing interests}

The authors declare that they have no competing interests.

\section{Author details}

${ }^{1}$ Departamento de Fisiología Médica Y Biofísica, Universidad de Sevilla, Av. Sánchez-Pizjuán 4, 41009 Sevilla, Spain. ${ }^{2}$ Instituto de Biomedicina de Sevilla, IBIS/Hospital Universitario Virgen del Rocío/CSIC/Universidad de Sevilla, Sevilla, Spain. ${ }^{3}$ Servicio de Animalario, Hospital Universitario Virgen Macarena (HUVM), 41009 Sevilla, Spain.

Received: 9 December 2020 Accepted: 18 May 2021

Published online: 25 May 2021

\section{References}

1. Pennington BF, Moon J, Edgin J, Stedron J, Nadel L. The neuropsychology of Down syndrome: evidence for hippocampal dysfunction. Child Dev. 2003;74:75-93.

2. Sago H, Carlson EJ, Smith DJ, Kilbridge J, Rubin EM, Mobley WC, et al. Ts1Cje, a partial trisomy 16 mouse model for Down syndrome, exhibits learning and behavioral abnormalities. Proc Natl Acad Sci USA. 1998;95:6256-61.

3. Troca-Marin JA, Alves-Sampaio A, Montesinos ML. An increase in basa BDNF provokes hyperactivation of the Akt-mammalian target of rapamycin pathway and deregulation of local dendritic translation in a mouse model of Down's syndrome. J Neurosci. 2011;31:9445-55.

4. Iyer AM, van Scheppingen J, Milenkovic I, Anink JJ, Adle-Biassette H, Kovacs GG, et al. mTOR Hyperactivation in down syndrome hippocampus appears early during development. J Neuropathol Exp Neurol. 2014;73:671-83.

5. Perluigi M, Pupo G, Tramutola A, Cini C, Coccia R, Barone E, et al. Neuropathological role of PI3K/Akt/mTOR axis in Down syndrome brain. Biochim Biophys Acta. 2014;1842:1144-53.

6. Troca-Marin JA, Casañas JJ, Benito I, Montesinos ML. The Akt-mTOR pathway in Down's syndrome: the potential use of rapamycin/rapalogs for treating cognitive deficits. CNS Neurol Disord Drug Targets. 2014;13:34-40

7. Andrade-Talavera Y, Benito I, Casañas JJ, Rodriguez-Moreno A, Montesinos ML. Rapamycin restores BDNF-LTP and the persistence of long-term memory in a model of Down's syndrome. Neurobiol Dis. 2015;82:516-25.

8. Huber KM, Kayser MS, Bear MF. Role for rapid dendritic protein synthesis in hippocampal mGluR-dependent long-term depression. Science. 2000;288:1254-7.

9. Costa-Mattioli M, Monteggia LM. mTOR complexes in neurodevelopmental and neuropsychiatric disorders. Nat Neurosci. 2013;16:1537-43.

10. Hou L, Klann E. Activation of the phosphoinositide 3-kinase-Akt-mammalian target of rapamycin signaling pathway is required for metabotropic 
glutamate receptor-dependent long-term depression. J Neurosci. 2004;24:6352-61.

11. Sarbassov DD, Ali SM, Sengupta S, Sheen JH, Hsu PP, Bagley AF, et al. Prolonged rapamycin treatment inhibits mTORC2 assembly and Akt/PKB. Mol Cell. 2006;22:159-68,

12. Zhu PJ, Chen CJ, Mays J, Stoica L, Costa-Mattioli M. mTORC2, but not mTORC1, is required for hippocampal mGluR-LTD and associated behaviors. Nat Neurosci. 2018;21:799-802.

13. Zhou Z, Hu J, Passafaro M, Xie W, Jia Z. GluA2 (GluR2) regulates metabotropic glutamate receptor-dependent long-term depression through $\mathrm{N}$-cadherin-dependent and cofilin-mediated actin reorganization. J Neurosci. 2011;31:819-33.

14. Vanderklish PW, Edelman GM. Dendritic spines elongate after stimulation of group 1 metabotropic glutamate receptors in cultured hippocampal neurons. Proc Natl Acad Sci USA. 2002;99:1639-44.

15. Luscher C, Huber KM. Group 1 mGluR-dependent synaptic long-term depression: mechanisms and implications for circuitry and disease. Neuron. 2010;65:445-59.

16. Bhakar AL, Dolen G, Bear MF. The pathophysiology of fragile X (and what it teaches us about synapses). Annu Rev Neurosci. 2012:35:417-43.

17. Hou L, Antion MD, Hu D, Spencer CM, Paylor R, Klann E. Dynamic translational and proteasomal regulation of fragile $\mathrm{X}$ mental retardation protein controls mGluR-dependent long-term depression. Neuron. 2006;51:441-54.

18. Tsai PT, Greene-Colozzi E, Goto J, Anderl S, Kwiatkowski DJ, Sahin M. Prenatal rapamycin results in early and late behavioral abnormalities in wildtype C57BL/6 mice. Behav Genet. 2013;43:51-9.

19. Troca-Marin JA, Alves-Sampaio A, Tejedor FJ, Montesinos ML. Local translation of dendritic RhoA revealed by an improved synaptoneurosome preparation. Mol Cell Neurosci. 2010;43:308-14.

20. Mi H, Ebert D, Muruganujan A, Mills C, Albou L, Mushayamaha T, Thomas PD. PANTHER version 16: a revised family classification, tree-based classification tool, enhancer regions and extensive API. Nucl Acids Res. 2020;49:D394-403.

21. Casañas JJ, Gonzalez-Corrales M, Urbano-Gamez JD, Alves-Sampaio A, Troca-Marin JA, Montesinos ML. CPEB1 is overexpressed in neurons derived from Down syndrome IPSCs and in the hippocampus of the mouse model Ts1 Cje. Mol Cell Neurosci. 2019;95:79-85.

22. Alves-Sampaio A, Troca-Marin JA, Montesinos ML. NMDA-mediated regulation of DSCAM dendritic local translation is lost in a mouse model of Down's syndrome. J Neurosci. 2010;30:13537-48.

23. Valenti D, Braidy N, De Rasmo D, et al. Mitochondria as pharmacological targets in Down syndrome. Free Radic Biol Med. 2018;114:69-83.

24. Valenti D, de Bari L, De Filippis B, Henrion-Caude A, Vacca RA. Mitochondrial dysfunction as a central actor in intellectual disability-related diseases: an overview of Down syndrome, autism, Fragile X and Rett syndrome. Neurosci Biobehav Rev. 2014;46(Pt 2):202-17.

25. Izzo A, Mollo N, Nitti M, Paladino S, Cali G, Genesio R, et al. Mitochondrial dysfunction in Down syndrome: molecular mechanisms and therapeutic targets. Mol Med. 2018;24:2.

26. Bordi M, Darij S, Sato Y, Mellen M, Berg MJ, Kumar A, et al. mTOR hyperactivation in Down Syndrome underlies deficits in autophagy induction, autophagosome formation, and mitophagy. Cell Death Dis. 2019:10:563.

27. Nosyreva ED, Huber KM. Metabotropic receptor-dependent long-term depression persists in the absence of protein synthesis in the mouse model of fragile X syndrome. J Neurophysiol. 2006;95:3291-5.

28. Park S, Park JM, Kim S, Kim JA, Shepherd JD, Smith-Hicks CL, et al. Elongation factor 2 and fragile $X$ mental retardation protein control the dynamic translation of Arc/Arg3.1 essential for mGluR-LTD. Neuron. 2008:59:70-83.

29. Nadif Kasri N, Nakano-Kobayashi A, Van Aelst L. Rapid synthesis of the X-linked mental retardation protein OPHN1 mediates mGluR-dependent LTD through interaction with the endocytic machinery. Neuron. 2001;72:300-15

30. Niere F, Wilkerson JR, Huber KM. Evidence for a fragile X mental retardation protein-mediated translational switch in metabotropic glutamate receptor-triggered Arc translation and long-term depression. J Neurosci. 2012;32:5924-36.

31. Nagerl UV, Eberhorn N, Cambridge SB, Bonhoeffer T. Bidirectional activitydependent morphological plasticity in hippocampal neurons. Neuron. 2004:44:759-67.

32. Sheng M, Erturk A. Long-term depression: a cell biological view. Philos Trans R Soc Lond B Biol Sci. 2014;369:20130138.
33. Benavides-Piccione R, Ballesteros-Yanez I, de Lagran MM, Elston G, Estivill $X$, Fillat $C$, et al. On dendrites in Down syndrome and DS murine models: a spiny way to learn. Prog Neurobiol. 2004;74:111-26.

34. Belichenko PV, Masliah E, Kleschevnikov AM, Villar AJ, Epstein CJ, Salehi A, et al. Synaptic structural abnormalities in the Ts65Dn mouse model of Down Syndrome. J Comp Neurol. 2004;480:281-98.

35. Belichenko PV, Kleschevnikov AM, Salehi A, Epstein CJ, Mobley WC. Synaptic and cognitive abnormalities in mouse models of Down syndrome: exploring genotype-phenotype relationships. J Comp Neurol. 2007:504:329-45.

36. Holbro N, Grunditz A, Oertner TG. Differential distribution of endoplasmic reticulum controls metabotropic signaling and plasticity at hippocampal synapses. Proc Natl Acad Sci USA. 2009;106:15055-60.

37. Shukkur EA, Shimohata A, Akagi T, et al. Mitochondrial dysfunction and tau hyperphosphorylation in Ts1Cje, a mouse model for Down syndrome. Hum Mol Genet. 2006;15:2752-62.

38. Bartolome A, Garcia-Aguilar A, Asahara SI, Kido Y, Guillen C, Pajvani UB, et al. MTORC1 regulates both general autophagy and mitophagy induction after oxidative phosphorylation uncoupling. Mol Cell Biol. 2017;37:e00441-17.

39. Chresta CM, Davies BR, Hickson I, et al. AZD8055 is a potent, selective, and orally bioavailable ATP-competitive mammalian target of rapamycin kinase inhibitor with in vitro and in vivo antitumor activity. Cancer Res. 2010;70:288-98

40. Siarey RJ, Villar AJ, Epstein CJ, Galdzicki Z. Abnormal synaptic plasticity in the Ts1Cje segmental trisomy 16 mouse model of Down syndrome. Neuropharmacology. 2005;49:122-8.

41. Scott-McKean JJ, Costa AC. Exaggerated NMDA mediated LTD in a mouse model of Down syndrome and pharmacological rescuing by memantine. Learn Mem. 2011;18:774-8.

42. Duchon A, Raveau M, Chevalier C, Nalesso V, Sharp AJ, Herault Y. Identification of the translocation breakpoints in the Ts65Dn and Ts1Cje mouse lines: relevance for modeling Down syndrome. Mamm Genome. 2011:22:674-84.

43. Moult PR, Correa SA, Collingridge GL, Fitzjohn SM, Bashir ZI. Co-activation of p38 mitogen-activated protein kinase and protein tyrosine phosphatase underlies metabotropic glutamate receptor-dependent long-term depression. J Physiol. 2008:586:2499-510.

44. Waung MW, Pfeiffer BE, Nosyreva ED, Ronesi JA, Huber KM. Rapid translation of Arc/Arg3.1 selectively mediates mGluR-dependent LTD through persistent increases in AMPAR endocytosis rate. Neuron. 2008:59:84-97.

45. Narayanan U, Nalavadi V, Nakamoto M, Pallas DC, Ceman S, Bassell GJ, Warren ST. FMRP phosphorylation reveals an immediate-early signaling pathway triggered by group I mGluR and mediated by PP2A. J Neurosci. 2007:27:14349-57.

46. Ceman S, O'Donnell WT, Reed M, Patton S, Pohl J, Warren ST. Phosphorylation influences the translation state of FMRP-associated polyribosomes. Hum Mol Genet. 2003;12:3295-305.

47. Sharp AH, MCPherson PS, Dawson TM, Aoki C, Campbell KP, Snyder SH. Differential immunohistochemical localization of inositol 1,4,5-trisphosphateand ryanodine-sensitive $\mathrm{Ca} 2+$ release channels in rat brain. J Neurosci. 1993:13:3051-63.

48. Jedlicka P, Vlachos A, Schwarzacher SW, Deller T. A role for the spine apparatus in LTP and spatial learning. Behav Brain Res. 2008;192:12-9.

49. Pick JE, Khatri L, Sathler MF, Ziff EB. mGluR long-term depression regulates GluA2 association with COPII vesicles and exit from the endoplasmic reticulum. EMBO J. 2017;36:232-44.

50. Pick JE, Ziff EB. Regulation of AMPA receptor trafficking and exit from the endoplasmic reticulum. Mol Cell Neurosci. 2018;91:3-9.

51. Togashi H, Abe K, Mizoguchi A, Takaoka K, Chisaka O, Takeichi M. Cadherin regulates dendritic spine morphogenesis. Neuron. 2002;35:77-89.

52. Huang W, Zhu PJ, Zhang S, Zhou H, Stoica L, Galiano M, et al. mTORC2 controls actin polymerization required for consolidation of long-term memory. Nat Neurosci. 2013;16:441-8.

\section{Publisher's Note}

Springer Nature remains neutral with regard to jurisdictional claims in published maps and institutional affiliations. 